\title{
Fruit morphology helps identifying evolutionary groups in Alpinieae (Zingiberaceae): inferences from phylogenetic analysis of gingers in Sri Lanka
}

\author{
P Karunarathne ${ }^{1,2,3^{*}}$, D Yakandawala ${ }^{2}$ and P Samaraweera ${ }^{2,3}$ \\ ${ }^{\prime}$ Department of Life Sciences, Texas A\&M University, Corpus Christi, Corpus Christi, Texas, USA. \\ ${ }^{2}$ Department of Botany, Faculty of Science, University of Peradeniya, Peradeniya. \\ ${ }^{3}$ Postgraduate Institute of Science, University of Peradeniya, Peradeniya.
}

Submitted: 10 Mar 2020; Revised: 01 September 2020; Accepted: 26 March 2021

\begin{abstract}
To assess the systematics and the phylogenetic placement of the members of the two important genera Alpinia Roxb. and Amomum Roxb. in Sri Lanka, molecular data of twelve in-group species together with three outgroup taxa of the family Zingiberaceae were extensively analysed for phylogenetic significance. The current analysis of the evolutionary relationships of the Sri Lankan members of the genera of interest, utilising DNA sequence data of the chloroplast genome regions trn L-F and trn S-fM, has resolved four groups of Alpinia and two major clades of Amomum with substantial parsimony analysis and Bayesian inferences consistency values. With new accessions from the entire native range of the family, this result points to the need for an inevitable re-circumscription of the genus Alpinia, and shows congruence to the recent reshuffling of the genus Amomum and the family Zingiberaceae, except for the placement of each genus as monophyletic groups in the context of our study. Here, we suggest swapping the group defining species of an Alpinia clade observed in previous studies. Finally, our study suggests the use of fruit morphology to distinguish among recognised groups for Sri Lankan species as they exhibit positive correspondence.
\end{abstract}

Keywords: Alpinia, Amomum, phylogeny, Sri Lanka, Zingiberaceae.

\section{INTRODUCTION}

The two largest genera Alpinia and Amomum of the family Zingiberaceae, not only show a wide geographical distribution (Kiew, 1982; Smith, 1990; Larsen et al., 1998; Wu \& Larsen, 2000; Sirirugsa, 2001) but also possess an array of homoplasious and plesiomorphic characters that make the classification of the genera problematic (Kress et al., 2002; Lamxay \& Newman, 2012). Recent phylogenetic analyses of Alpinia and Amomum revealed the polyphyletic nature of the genera (Rangsiruji et al., 2000a; Xia et al., 2004; Kress et al. 2005; Boer et al., 2018) rejecting the previous classification which was based solely on morphological characters (Schumann, 1904; Smith, 1990). Boer et al. (2018) presented a more thorough phylogenetic analysis of Alpiniae, concluding the presence of 10 Amomum clades and six Alpinia clades. Further, they proceeded with re-circumscription of the Amomum clade by resurrecting three genera (Conamomum, Meistera, and Wurfbania) and describing three new genera (Epiamomum, Lanxangia, and Sundamomum). However, the current phylogenetic and evolutionary analyses of the two genera are far from being completed as they lack many representative species (e.g. species from South and Southeast Asia). Furthermore, only a few of the Sri Lankan species have been used in the aforementioned studies [Amomum pterocarpum, Meistera echonocarpa (formerly Amomum echinocarpum), Alpinia abundiflora and Alpinia fax] despite the fact that there are several taxonomically paramount species occurring in Sri Lanka (Burtt \& Smith, 1983). In this paper, phylogenetic placement of

*Corresponding author (piyal.karunarathne@tamucc.edu; (D https://orcid.org/0000-0002-1934-145X) 
the Sri Lankan members of the two genera of interest is comparatively and comprehensively discussed, using the inferences drawn from the DNA sequence analysis.

With the recognition of the polyphyletic origin of the previously recognised tribes of the family Zingiberaceae (Sakai \& Nagamasu, 1998; Rangsiruji et al., 2000a; Kress et al., 2002; Harris et al., 2003; Kress \& Specht, 2005), several generic-level phylogenetic studies addressed the evolutionary relationships of the genera Alpinia (Rangsiruji et al., 2000b; Kress et al., 2005) and Amomum (Kaewsri, 2006; Kaewsri et al., 2007; Droop, 2012) as well as the tribe Alpinieae (Kaewsri et al., 2007; Kress et al., 2007, Boer et al., 2018) nesting two genera in comparative assessments. A common conclusion of these studies was that the members of the tribe do not follow the previous classification system and instead they tend to show different inter- and infra-generic evolutionary relationships indicating the polyphyletic nature of Alpinia and Amomum.

Nuclear and plastid DNA sequence analysis of Alpinia indicated that taxa described under this genus are closer to other genera of Alpinieae than they are to each other making classification of the tribe difficult (Rangsiruji et al., 2000a; Kress et al., 2005) due to its polyphyletic origin. Rangsiruji et al. (2000a) identified four separate clades of Alpinia whereas Kress et al. (2005) and Boer et al. (2018) described the separation of the genus into six groups. However, none of these studies agreed with the comprehensive infra-generic classification of Alpinia by Smith (1990), where she identified two subgenera within the genus encompassing 221 species. Similarly, during an analysis to assess the species boundaries of Aframomum, Harris et al. (2000) suggested that Amomum might be paraphyletic. Later studies by Xia et al. (2004) demonstrated the segregation of the genus Amomum into three major clades and they used fruit morphology to explain the clades observed. In another study by Kaewsri et al. (2007) using amplified fragment length polymorphism (AFLP) makers to analyse the phylogenetic relationships of Thai Amomum showed the positive correspondence of fruit morphology to the clades observed. Droop (2012) explained the presence of at least seven groups of Amomum, inferred by the results of the phylogenetic analysis using Internal transcribed spacer (ITS) and matK data, whereas Boer et al. (2018) found 10 clades of Amomum using the same gene regions and they used both anther crest and fruit morphology in combination to discriminate the clades.
Although Alpinia and Amomum add the highest number of endemic species to the ginger family in Sri Lanka (Burtt \& Smith, 1983), taxonomy and phylogenetic relationships of the members of these two genera has been poorly studied. The last taxonomic revision of the family Zingiberaceae in Sri Lanka was in 1983 (Burtt \& Smith, 1983). Since then, several major revisions have taken place in the world utilising new phylogenetic tools, which resulted in major changes in the classification of the family (Rangsiruji et al., 2000a; Xia et al., 2004; Kress et al., 2005; de Boer et al., 2018). More importantly, none of the Sri Lankan endemic species had been used in any of the previous phylogenetic analyses. This observation justifies the need for a thorough phylogenetic account of Sri Lankan members of the family Zingiberaceae. As a pioneering step, the present study employed molecular data to determine evolutionary relationships among the members of the two genera Alpinia and Amomum in Sri Lanka and to compare the results with the current major revisions.

The goals of this study are: to construct phylogenetic hypothesis of interspecific and intergeneric relationships of the two genera primarily focusing on Sri Lankan species and compare the results with currently existing classifications; and to assess the congruence of several morphological characters with the molecular analysis results.

\section{METHODOLOGY}

\section{Sampling}

\section{Ingroup taxa}

Representative samples from 12 species of both genera were collected for the study (Figure 1 and 2). These included two native Alpinia species, four species of nonnative Alpinia, four native Amomum species, one endemic Amomum species, and a new record of Amomum from Sri Lanka [Wurfbainia villosa var. zeylanicus (formerly Amomum villosum zeylanicus)] - Karunarathne et al. (2014). Unfortunately, four species of endemic Amomum (A. nemorale, A. graminifolium, A. benthamianum, and A. trichostachyum), one species of endemic Alpinia (A. rufescens) and one native Amomum species ( $A$. hypoleucum) were not found during comprehensive field sampling. Most of these species have not been collected for more than 100 years and almost all types of localities are under intense human activities. Therefore, we present 
Table 1: List of species of Sri Lankan Alpinia Roxb. and Amomum Roxb. showing the latest National Red List (2012) status of the native and endemic species and the GenBank accession numbers for the two sequences trn L-F and trn S-fM of each studied species.

\begin{tabular}{|c|c|c|c|c|c|c|}
\hline \multirow[t]{2}{*}{ Species } & \multirow{2}{*}{$\begin{array}{l}\text { Suggested infra-generic } \\
\text { clade (Xia et al., 2004; } \\
\text { Kress et al., 2005) }\end{array}$} & \multirow{2}{*}{$\begin{array}{l}\text { National Red } \\
\text { List status } \\
\text { (MOE, 2012) }\end{array}$} & \multirow{2}{*}{$\begin{array}{c}\text { Last } \\
\text { collection }\end{array}$} & \multirow{2}{*}{$\begin{array}{l}\text { Collected } \\
\text { in this } \\
\text { study }\end{array}$} & \multicolumn{2}{|c|}{ GenBank accession numbers } \\
\hline & & & & & $\operatorname{trnL}$-trnF & $\operatorname{trnS}$-trnfM \\
\hline Alpinia abundiflora & A. fax clade & $\mathrm{LC}$ & 2008 & Yes & KF748154 & KF748169 \\
\hline Alpinia fax & A. fax clade & VU & 1996 & Yes & KF748153 & KF748168 \\
\hline Alpinia rufescens $\nleftarrow$ & A. fax clade & $\mathrm{CR}(\mathrm{PE})$ & 1862 & No & & \\
\hline Amoтит pterocarpum & - & EN & 1987 & Yes & KF748162 & KF748177 \\
\hline Amomum masticatorium & - & EN & 1988 & Yes & KF748160 & KF748175 \\
\hline Amomum fulviceps & - & VU & 1973 & Yes & KF748159 & KF748174 \\
\hline Aтотит hyроleuсит & - & $\mathrm{CR}(\mathrm{PE})$ & 1861 & No & & \\
\hline Meistera echinocarpa & - & VU & 1989 & Yes & KF748161 & KF748176 \\
\hline Amomum graminifolium $\ddagger$ & - & EN & 1994 & No & & \\
\hline Amomum acuminatum $\ddagger$ & - & $\mathrm{CR}(\mathrm{PE})$ & 1855 & Yes & KF748157 & KF748172 \\
\hline Amomum trichostachyum $\ddagger$ & - & EN & 1973 & No & & \\
\hline Amomum nemorale $\$$ & - & $\mathrm{CR}(\mathrm{PE})$ & 1861 & No & & \\
\hline Amomum benthamianum & - & $\mathrm{CR}(\mathrm{PE})$ & 1864 & No & & \\
\hline Wurfbainia villosa zeylanicus & - & - & - & & KF748158 & KF748173 \\
\hline \multicolumn{7}{|l|}{ Non-native species } \\
\hline Alpinia galanga & A. galanga clade & - & - & Yes & KF748152 & KF748167 \\
\hline Alpinia calcarata & A. zerumbet clade & - & - & Yes & KF748151 & KF748166 \\
\hline Alpinia malaccensis & A. zerumbet clade & - & - & Yes & KF748155 & KF748170 \\
\hline Alpinia zerumbet & A. zerumbet clade & - & - & Yes & KF748156 & KF748171 \\
\hline \multicolumn{7}{|l|}{ Out-group species } \\
\hline Zingiber cylindricum & - & - & - & Yes & KF748148 & KF748163 \\
\hline Zingiber sp. & - & - & - & Yes & KF748149 & KF748164 \\
\hline Hedychium coronarium & - & - & - & Yes & KF748150 & KF748165 \\
\hline
\end{tabular}

LC - least concerned; VU - vulnerable; EN - endangered; CR (PE) - critically endangered (possibly extinct)

t: endemic species

an adequate sampling of extant taxa of the two genera in Sri Lanka (Table 1).

\section{Outgroup taxa}

Two representative species of Zingiber (Z. cylindricum and Zingiber sp.) and one species of Hedychium ( $H$. coronarium) were collected during the field sampling for out-group taxa. For a better comparison of the overall phylogeny and the geographical distribution of the phylogenetic clusters, DNA sequences of trnL$\operatorname{trn} \mathrm{F}$ intergenic spacer region of four Aframomum, three Renealmia, and one Elettariopsis accessions were also downloaded, following a nucleotide blast from GeneBank for outgroup taxa (supplementary Table 1). These three genera are sister groups to the studied two genera in the present study (Kress \& Specht, 2005; Kress et al., 2007).

\section{DNA extraction and sequencing}

Fresh leaf samples dried with silica beads were used for DNA extractions. Genome DNA was extracted using a modified Doyle and Doyle (1987) CTAB protocol with 
few additional purification steps: suspended DNA in TE was treated with ProteinaseK and RNase followed by phenol chloroform extraction and sodium acetate precipitation of DNA. PCR amplification was done for two chloroplast gene regions trn L-F and trn S- $f \mathrm{M}$, using trn L-F (Taberlet et al., 1991) and trn S- $f$ M (Shaw et al., 2005) primer pairs, respectively. The chloroplast genome regions $m a t \mathrm{~K}$, and $\operatorname{trn} \mathrm{L}-\mathrm{F}$ together with nuclear ribosomal ITS regions have been explicitly used in evolutionary studies of the family Zingiberaceae (Johnson \& Soltis, 1994; Baldwin et al., 1995; Kress et al., 2002). However, only the chloroplast intergenic spacer trn L-F and the non-coding region trn $\mathrm{S}-\mathrm{fM}$ were used because in the initial steps, the primers that were used for ITS and matK regions failed to amplify the desired region for several species (A. echinocarpum, A. pterocarpum, and A. fax) and two species produced multiple bands for ITS region (A. acuminatum and A. fulviceps). The region trn $\mathrm{S}-\mathrm{fM}$ has been documented to be informative in phylogenetic studies (Shaw et al., 2005; Minami et al., 2009).

According to the manufacturers' recommendations all amplifications used Promega GoTaq ${ }^{\circledR}$ Flexi DNA polymerase (Madison, WI, USA). Eppendorf Mastercycler® thermal cycler (Hauppauge, NY, USA) with the following programs was used for PCR amplifications.

trn $L-F$ region: preheat at $80{ }^{\circ} \mathrm{C}$ for 3 min, 2 cycles with 3 temperature segments $\left(94{ }^{\circ} \mathrm{C}\right.$ for $2 \mathrm{~min}, 50{ }^{\circ} \mathrm{C}$ for $40 \mathrm{~s}$ and $72{ }^{\circ} \mathrm{C}$ for $2 \mathrm{~min}), 30$ cycles with 3 temperature segments $\left(94^{\circ} \mathrm{C}\right.$ for $30 \mathrm{~s}, 50^{\circ} \mathrm{C}$ for $30 \mathrm{~s}$ and 72 for ${ }^{\circ} \mathrm{C} 1 \mathrm{~min}$ ) and final extension $72{ }^{\circ} \mathrm{C}$ for $8 \mathrm{~min}$.

trn S-fM region: preheat at $94{ }^{\circ} \mathrm{C}$ for $3 \mathrm{~min}, 30$ cycles with 3 temperature segments $\left(94^{\circ} \mathrm{C}\right.$ for $30 \mathrm{~s}, 50{ }^{\circ} \mathrm{C}$ for $30 \mathrm{~s}, 72{ }^{\circ} \mathrm{C}$ for $1 \mathrm{~min}$ ) final extension $72^{\circ} \mathrm{C} 8 \mathrm{~min}$.

PCR product purification and DNA sequencing were done by Macrogene Inc. Korea (Sanger sequencing: 96-capillary 3730XL DNA Analyzer: Applied Biosystems $\left.{ }^{\circledR}\right)$. Same primerpairs as in PCR amplifications were used in sequencing for the respective gene region. Raw sequences were screened and assembled in SeqMan Pro, DNAStar ${ }^{\circledR}$ Lasergene 8.1 (DNASTAR, Inc., 2009). Assembled contigs were edited using BioEdit (ver. 7.1.9) (Tom Hall, Ibis Biosciences, California, USA). Edited sequences were then aligned using ClustalX 2.1 (Larkin et al., 2007). Alignment files were further edited in BioEdit to process unaligned bases. This was repeated for all sequences of the studied two DNAs separately. A combined analysis of the two regions was also performed to obtain better resolved trees and thereby to estimate phylogeny with the strongly supported results (Nixon \& Carpenter, 1996).

Furthermore, to conduct a more inclusive sampling of the two genera, sequences of both Alpinia and Amomum were downloaded from GeneBank to analyse with the accessions from the present study. DNA sequences of $\operatorname{trn} \mathrm{L}-\operatorname{trn} \mathrm{F}$ intergenic spacer region of six Alpinia and seven Amoтиm accessions were downloaded following a nucleotide blast from GeneBank (Supplementary Table 1).

\section{Phylogenetic analysis}

\section{Maximum Parsimony Analysis (MPA)}

MPA of the aligned sequence data was accomplished using PAUP* 4.0 (Swofford, 2003) on a power Macintosh G4. Heuristic search strategies were used in 1000 Tree Bisection Reconnection (TBR) branch swapping replicates of random taxon addition with MULPARS in effect. The majority-rule strict consensus tree assembly was used to build the most parsimonious trees. All positions were weighted equally; gaps were treated as missing values. The Consistency Index (CI) and Retention Index (RI) values for tree topologies were also calculated with PAUP. Bootstrap analyses (Felsenstein, 1985) were conducted using PAUP with a simple addition of 1000 fast-swap replicates to 100 tree topologies with a $50 \%$ confidence.

\section{Bayesian Inferences}

Bayesian analysis was used to draw model based phylogenetic inferences (Yang \& Rannala, 1997; Larget \& Simon, 1999) from the DNA sequence data. MrBayes (Huelsenbeck \& Ronquist, 2001) was used for the analysis to obtain the posterior probabilities (PP). Models for the sequence evolution was determined using jModeltest (Posada, 2008) and the following parameters were used in the analysis; GTR, nst $=6$, rates $=$ inverse gamma, statefreqpr $=$ fixed (equal). The analysis comprised generations of 10,000,000 Markov Chain Monte Carlo (MCMC) chains with a sampling frequency of every 10,000 generations. The initial $25 \%$ samples from each run were discarded as burn-in, after which the run was summarised as a majority rule consensus tree and the posterior probability values were saved in MrBayes. Separate analysis of the two regions and the combined analysis produced a similar tree topology for the strict consensus. Therefore, only the combined tree is presented here. 


\section{RESULTS AND DISCUSSION}

\section{Analysis of $t r n$ L-F intergenic spacer data}

A total of 449 parsimony-informative characters were present in the $\operatorname{trn} \mathrm{L}-\mathrm{F}$ region, which produced 5473 equally parsimonious trees in more than 270,000 rearrangement steps in parsimony analysis. Strict consensus of these trees (Supplementary Figure 1) placed all the in-group taxa in a monophyletic clade (bootstrap $91 \%$ ) separating out-group taxa. Alpinia and Amomum were placed in two separate clades ( $A$ and $B$ in Supplementary Figure 1) with moderate and strong bootstrap values: 65 and 100, respectively. Hence, genera Alpinia and Amomum in Sri Lanka are strongly supported as monophyletic. Bayesian inferences also supported this observation with a high PP value of one.
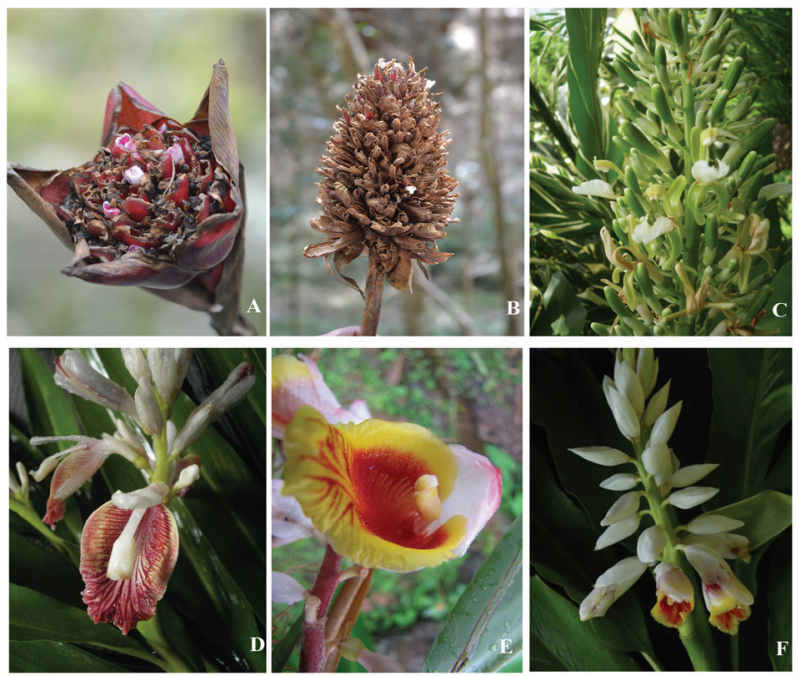

Figure 1: Floral pictures of some Alpinia species found in Sri Lanka; (A) A. abundiflora, (B) A. fax, (C) A. galanga, (D) A. calcarata, (E) A. maleccensis, (f) A. zerumbet

Two major clades were observed in the Amomum group: Am I, A. pterocarpum (bootstrap $100 \%$ ) and Am II, A. echinocarpum, A. villosum zeylanicus, A. masticatorium, A. fulviceps and $A$. acuminatum (bootstrap $93 \%$ ). Separation of these two clades were also observed in the Bayesian analysis with PP values of 1.00 and 0.98 , respectively. Four clades were identified in the Alpinia group: Alp I, Alp II, Alp III, and Alp IV. A. abundiflora and $A$. fax formed a separate group (Alp I) basal to the rest of the Alpinia with moderate bootstrap values (69\%) and with high Bayesian support $(\mathrm{PP}=0.98)$. The other three clades (Alp II- A. galanga; Alp III- A. calcarata; Alp $I V$ - A. malaccensis and A. zerumbet), possess moderate support values.

\section{Analysis of $t r n$ S-fM intergenic spacer data}

This region resulted in 3673 equally parsimonious trees in more than 670,000 rearrangement steps in the MPA. This region harboured 140 parsimony-informative characters (Supplementary Figure 2). Strict consensus of these trees also produced two major groups of ingroup species with moderate bootstrap values and high PP values: A) Alpinia clade (bootstrap $=69 \%$, $\mathrm{PP}=1$ ); B) Amomum clade (bootstrap $=50 \%, \mathrm{PP}=1$ ) (Supplementary Figure 2). However, all in-group species formed a single monophyletic clade providing higher support values $(87 \%, \mathrm{PP}=1)$. Same three clades that were observed with trn L-F for the Amomum group was also observed with this analysis but with different bootstrap values. A. fax and A. abundiflora formed the basal clade $(A l p I)$ of the Alpinia group with strong support values (bootstrap $80 \%, \mathrm{PP}=1$ ). Despite the low PP value (0.58), the rest of the Alpinia further split into three distinctive groups separating A. galanga (Alp II); A. calcarata (Alp III); A. zerumbet and A. malaccensis (Alp IV).
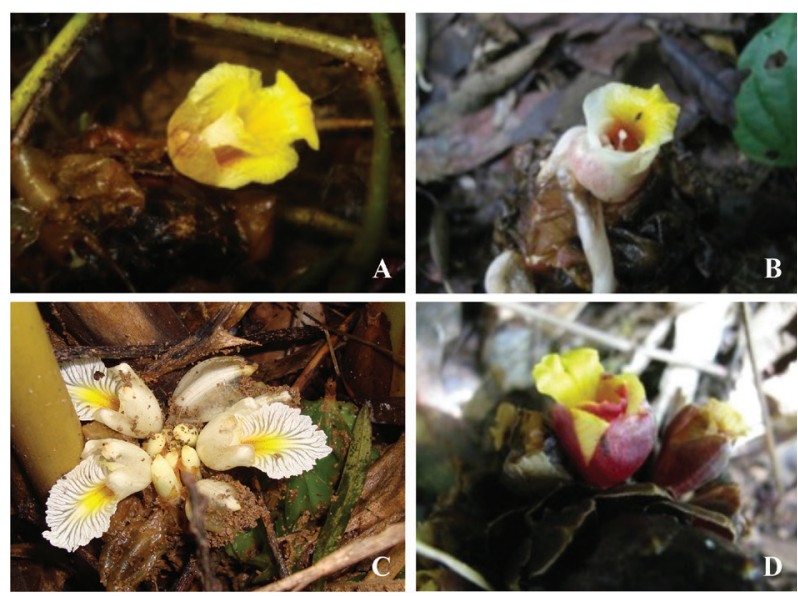

Figure 2: Floral pictures of few Sri Lankan Amomum species; (A) A. masticatorium, (B) A. echinocarpum, (C). A. pterocarpum, (D). A. fulviceps 


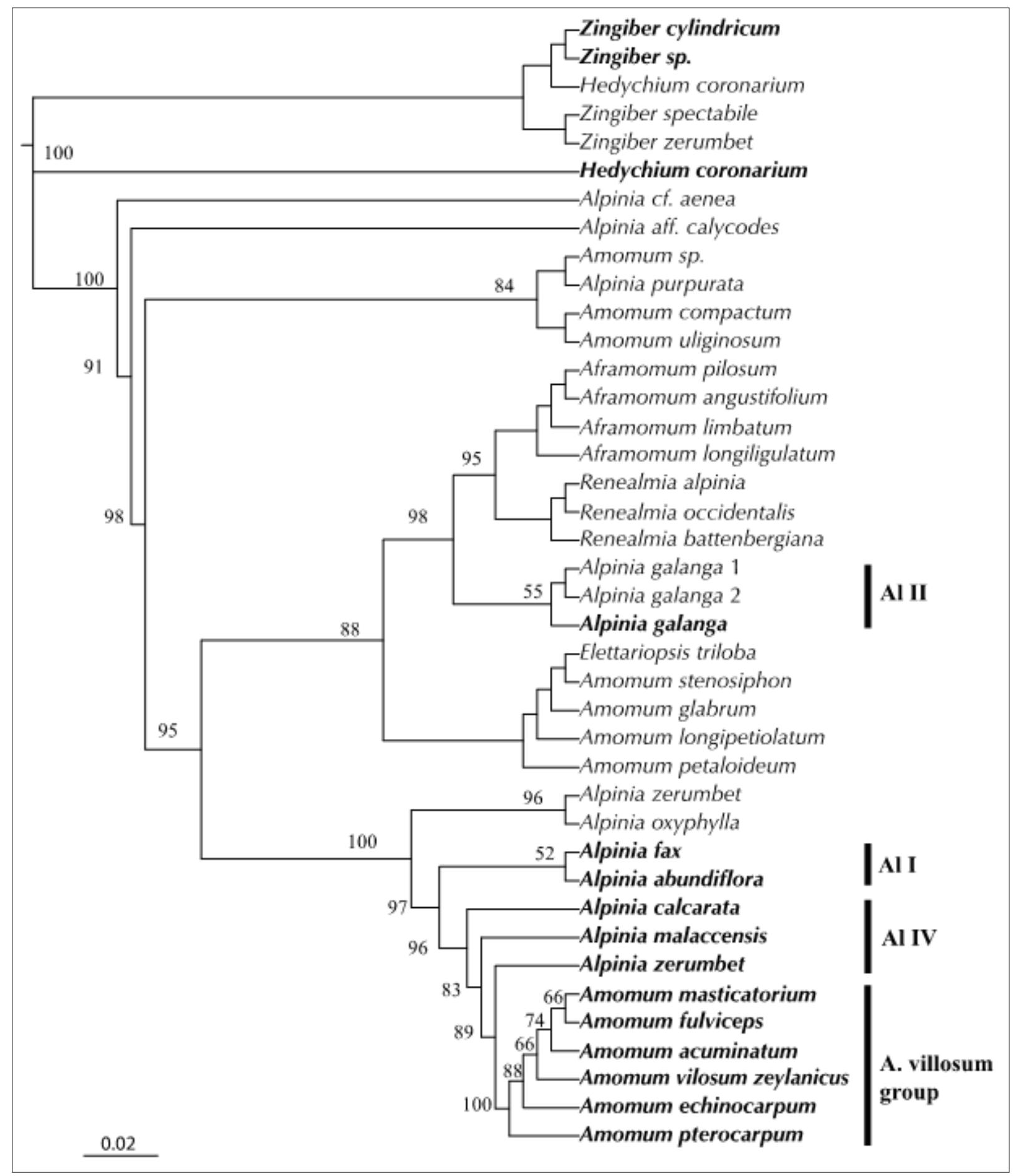

Figure 3: Best trees resulting from the parsimony analysis of the GeneBank accessions and the data from the present study of trn $L-F$ intergenic spacer region (length $=510$; consistency index $=0.901$; retention index $=0.966$; rescaled consistency index $=0.900$ ); branch labels: above - bootstrap values, Al I, II, IV - Alpinia groups that corresponds to Kress et al. (2005), A. villosum group Amomum group that corresponds to Xia et al. (2004) and Wurfbainia group in Boer et al. (2018). 


\section{Analysis of the combined dataset}

Combined analysis resolved Sri Lankan Alpinias into three major clades (i.e. Al I, Al II, Al IV), and Amomum into one group (i.e. A. villosum group sensu Xia et al., 2004 and Wurfbainia group sensu Boer et al., 2018) (Figure 3, also see Supplementary Figure 3). A. galanga grouped with GeneBank accessions in a separate group while all the other Alpinia were resolved in sister clades. Interestingly, $A$. fax and $A$. abundiflora resolved into one clade in the latter while the rest of the species were separated in individual branches with strong statistical support (Figure 3). Within the Amomum clade, we see the same inner groups as were resolved in separate analyses. Nevertheless, all the clades were strongly supported by bootstrap values except for two branches within the Amomum clade.

Overall, Alpinia and Amomum in Sri Lanka form a monophyletic group with strong phylogenetic support values (bootstrap $100 \%, \mathrm{PP}=1$ ). All the Amomum species formed a monophyletic clade (bootstrap $100 \%, \mathrm{PP}=1$ ) where they were further divided into two monophyletic groups separating basal clade Am I: A. pterocarpum (bootstrap: $100 \%, \mathrm{PP}=1$ ) and the second clade $\mathrm{Am} \mathrm{II}$ nesting all the other species (bootstrap 100, PP $=0.98$ ) (Supplementary Figure 3). A. fax and A. abundiflora were placed separately $(A l I)$ from other Alpinias with high support values (bootstrap $97 \%, \mathrm{PP}=1$ ). Although the other three Alpinia accessions nested together with all the other Sri Lankan species, A. galanga clustered with other accessions of the species from the GeneBank (Al II). Al IV clade nested non-native - A. zerumbet and A. malaccensis (bootstrap 100, $\mathrm{PP}=1$ ).

Bayesian analysis of the trn L-F and trn S-fM sequence data resulted in cladograms similar to that of the MPA. All the clades observed in the maximum parsimony analysis were supported with higher posterior probability (PP) values in the Bayesian analysis. The two genera are monophyletic with strong PP value of 1.00 . The Alpinia group formed two clades in the analysis separating $A$. abundiflora and $A$. fax from the rest with a PP value of 0.98. Overall, the Bayesian inferences of the phylogenetic trees is congruence with the results of MPA.

The complexity of the classification of the two polyphyletic genera Alpinia and Amomum has been acknowledged by many authors (Smith 1990;
Larsen et al., 1998; Kress et al., 2002). As a result, many researchers who were interested in the family Zingiberaceae have dealt with taxonomy, phylogeny and the classification of these two genera. Remarkably, the phylogenetic relationships of the members of the family in Sri Lanka have never been assessed and none of the endemic species have been assessed in any of the recent phylogenetic studies of the family (e.g. Kress et al., 2002, Xia et al., 2005, Boer et al,. 2018, Droop 2019). Hence, the current study attempted phylogenetic analysis of the Sri Lankan members of the two genera Alpinia and Amomum. Results of the present analysis provides better insight to the evolutionary relationships of the studied species in Sri Lanka.

According to the latest phylogenetic analysis of Amomum group (de Boer et al., 2018), Sri Lankan taxa of the Amomum group consist of three genera (i.e. Amomum, Wurfbainia and Meistera). However, the present study has not resulted in similar groups, and was rather congruent with the previous studies of the family Zingiberaceae (Rangsiruji et al., 2000a; Kress et al., 2002) by resolving only two clades. This may be due to the limited sampling in our study representing all the species of Amomum group. Although the present analysis does not include accessions representing all the genera of the family, our study highlighted two Amomum clades with strong statistical support (Figure 3). Therefore, in congruence with infra-generic relationships that were illuminated in recent studies (Kress et al., 2007; Droop, 2012), it can be concluded that Sri Lankan members of the two genera of interest make two evolutionary groups. Reduced staminodes, capsule: globose, echinate or irregular shaped, and relatively short stamen can be listed as a combination of features that characterise the separation of the clade.

\section{Alpinia}

Although all the Alpinia species studied in this analysis formed a monophyletic group, the separation of the clades within the genus (i.e. Alp I, Alp II, Alp III and Alp IV) agrees with the broader studies of the family (Rangsiruji et al., 2000a; Kress et al., 2002). These groups are in congruence with the recent phylogenetic studies on the family (Rangsiruji et al., 2000a; Kress et al., 2002, 2005, 2007) and also confirm the incongruence with earlier morphological treatments (Schumann, 1904; Smith, 1990). 
A. abundiflora and A. fax were placed as the basal group (Alp I), separately from all the other members of the genus with strong support values in both MPA and Bayesian analyses of the molecular data. Recognition of this clade was also described in phylogenetic analyses of Alpinia by Kress et al. (2005) and Rangsiruji et al. (2000b). As the latter study explained, these species (namely $A$. fax clade) are characterised by the presence of capitate, usually radical inflorescence surrounded by a world of sterile bracts; fertile bracts subtending a cincinnus of several flowers. Furthermore, this observation reinforces the suggestion by Kress et al. (2007) that these species require a new generic name. Kress et al. (2005) also suggested that the inclusion of $A$. rufescens in this clade is appropriate since this species also shares this distinctive morphological character combination. A. rufescens has been recorded only in Sri Lanka. It is only known from the type locality and has never been recollected since its type gathering (1862). During our extensive field sampling efforts (comprised of more than 25 locations) it was observed that the type locality of $A$. rufescens is no longer a potential area to support these species since the area is under intense human activities. This species was not found from any other location either. After close and careful observation of the characters of this clade, it could be suggested that $A$. abundiflora be used as the clade defining species instead of $A$. fax because A. abundiflora possesses typical characters such as capitate inflorescence, occurrence of the inflorescence either (rarely) on the vegetative stem or on a separate basal peduncle and typically a cincinnus of seven (7) flowers. These are also shared with $A$. rufescens (except for the number of flowers in a cincinnus). On the other hand, the inflorescence of $A$. fax rather elongates with age and it bears a lesser number of flowers in a cincinnus (seldom up to six flowers). Further, Karunarathne et al. (2015) reported the confusion of morphological characters of $A$. fax that was also presumably recorded in South India (Kumar et al., 2002).

Although the inclusion of Alpinia galanga with the rest of Sri Lankan Alpinia (except Alp I) showed weak support values (bootstrap $56 \%, \mathrm{PP}=0.58$ : combined analysis), the separation of groups Alp I, through Alp $I V$ was strongly supported. The clade Alp I separated A. abundiflora and A. fax from the rest with strong support (bootstrap $75 \%, \mathrm{PP}=0.98$ ). Next to the A. abundiflora clade, Alp II isolated A. galanga basal to the Al group. A. galanga clade is characterised by higher number of flowers in the branched inflorescence, smaller size of flowers, clawed labellum and the glabrous ovary. Inclusion of additional species such as A. nigra (not found in our field observations) might better explain these characters. Although A. calcarata was included as a member of the A. zerumbet clade in previous studies, the present results placed it as a separate clade (Alp III). Linear-lanceolate shape of the lamina and the reduced lamina width along with the smaller sized fruits can be listed as deviating characters. A. zerumbet and A. malaccensis formed the terminal clade with strong bootstrap support. Besides the robustness of the habit of the plant, relatively large, globose fruits are characteristic to this clade.

\section{Amomum}

All the studied Sri Lankan Amomum species resolved into two major clades ( $A m I$ and $A m I I)$. This exhibits congruence with recent evolutionary analyses of the genus (Xia et al., 2004; Kaewsri et al., 2007; Droop, 2012, Boer et al., 2018). Results of the current analysis also do not correspond to earlier infra-generic classification of the genus (e.g. Schumann 1904; Smith 1990).

A. pterocarpum was placed as the basal most lineage (clade $\mathrm{Am} \mathrm{I}$ ) of the Amomum group. The clade is characterised by the presence of ribbed capsule with wings, sub-globose inflorescence with quickly deciduous bract and bracteoles. Am II clade resembles the $A$. maximum clade which was observed in the study by Xia et al. (2004) and other studies (Kress et al., 2007; Droop, 2012). The main characteristic feature of this group is the presence of smooth or winged fruit coat (Xia et al., 2004). Am II placed all the other members of the genus (A. echinocarpum, A. masticatorium A. fulviceps and $A$. acuminatum, $A$. villosum zeylanicus) in a single clade with strong branch support values. The most conspicuous morphological characters that shared among these species are slender basal peduncle covered with scaly sheaths, ovoid to elongated inflorescence, brownred bracts and bracteoles, tri-lobed anther appendage, bifid labellum and echinate fruits. This is in congruence with the recent evolutionary analysis of the genus. Xia et al. (2004) identified this group as A. villosum clade with echinate fruits being a distinctive character and later studies confirmed this placement (Xia et al., 2004; Kress et al., 2007; Droop, 2012). The new record of species Amomum villosum var. zeylanicus shows the typical characters that Xia et al. (2004) highlighted for the group. In contrast to this, Boer et al. (2018) separated these species into two separate genera: i) Meistera M. echinocarpa, M. masticatorum; ii) Wurfbainia W. villosa (var. zeylanicus), respectively. They described echinate fruits and semilunar anther crest for Meistera and echinate fruits and eared anther crest for Wurfbainia as conspicuous characters of the two genera. However, 


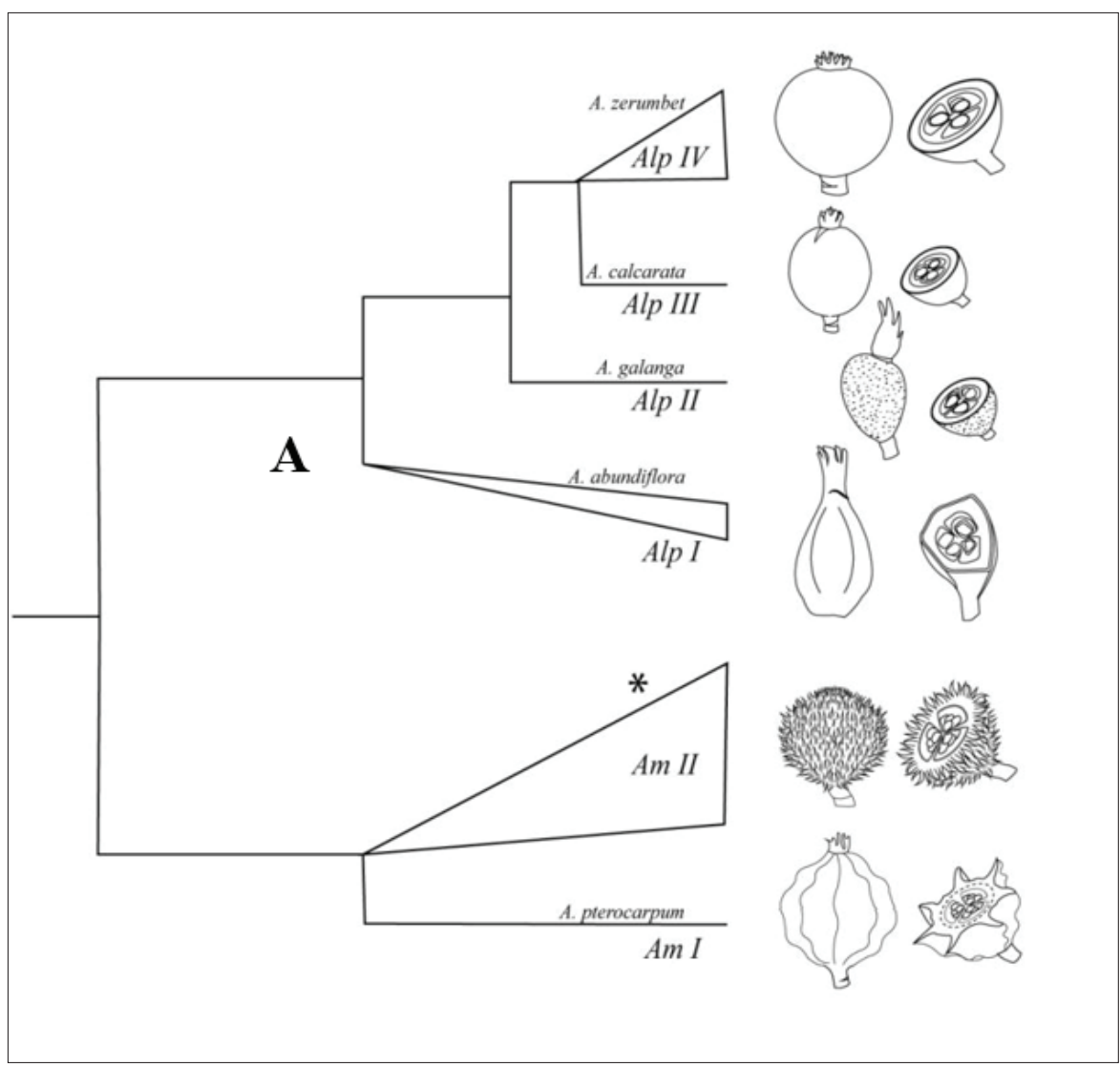

Figure 4: Tree depicting the fruit morphology attribution for the characterisation of the Alpinia and Amomum clades observed in Sri Lanka, obtained from the molecular data analysis; A. Alpinia clade, B. Amomum clade; *. Am II clade: Amomum group of species bearing echinate fruits (A. echinocarpum, A. masticatorium, A. fulviceps, A. acuminatum, and A. villosum zeylanicus.) (Drawings are according to their relative size)

this separation of polyphyletic clades was not observed in the present study.

Moreover, after comprehensive observation of the morphological characters of each clade resulted in the current phylogenetic analysis, besides the abovementioned group specific characters, fruit morphology of the studied species can be effectively utilised to separate different clades of the Sri Lankan members of Alpinia and Amomum. Figure 4 shows a detailed attribution of the fruit morphology of the groups for this context. However, we admit that we are not the first to use the fruit morphology to separate phylogenetic clades in the family Zingiberacea (Kress et al., 2002; Xia et al., 2005; Droop et al., 2012; Boer et al., 2018). Nevertheless, the use of the fruit morphology for Sri Lankan species presents an efficient strategy.

\section{Sri Lankan gingers in a global phylogeny}

The three Alpinia groups observed in our analysis are in close congruence with the most recent thorough analysis of the genus (Kress et al., 2005). Most importantly the analysis shows that Alpinias are not monophyletic, contrary to our analysis only with Sri Lankan species (Figure 4). This is expected as several other evolutionary groups in the family included in the analysis, and as observed in the phylogenetic analysis of the family (Kress et al., 2002; 2005; de Boer 2018). In contrast, the Amoтum species in Sri Lanka formed a monophyletic group with strong bootstrap support (100 \%). Furthermore, this resolution of one Amomum clade in Sri Lanka corresponds to the same Amomum villosum clade as in Xia et al. (2004) of the Amomum phylogeny. This suggests that all the Sri Lankan species of the genus 
evolved from one common ancestor although the genus itself in the region is not monophyletic. However, none of the other species of Amomum in this group were included in the previous evolutionary analyses of the genus. Therefore, a comparison of the results of this study is not appropriate. Most importantly, even though the evolutionary groups within the two genera slightly changed with the global phylogeny, our use of the fruit morphology still applies to the evolutionary groups found in Sri Lanka (Figure 4). Moreover, this observation can further be extended to identify corresponding clades of the two genera in other regions as well, as they show high congruence to previous studies by Xia et al. (2004), Kress et al. (2005) and Boer et al. (2018).

Overall, the current analysis of the evolutionary relationships of Sri Lankan Alpinia and Amomum utilising DNA sequence data of the chloroplast genome regions trn $L-F$ and trn $S$-fM and the combined dataset resolved four groups of Alpinia and two major clades of Amomum. This result is in congruence and consistent with recent phylogenetic analyses of the two genera using molecular data to a certain extent, except for the placement of each genus as monophyletic groups in the context in the present analysis. This discrepancy in comparison to other recent studies seems to arise from the fact that none of the endemic Sri Lankan species were used in previous studies. Finally, the present study suggests using the fruit morphology to distinguish the observed groups for Sri Lankan species because they exhibit positive correspondence with the fruit morphology, which is also consistent.

\section{Acknowledgement}

This research project was supported by the National Science Foundation of Sri Lanka (Grant SIDA/2007/ BT/02). The support and services provided by the Forest Department of Sri Lanka, Department of Wildlife Conservation Sri Lanka and the National Herbarium of Sri Lanka is also appreciated.

\section{Conflict of interest}

All the authors of this manuscript declare that no conflict of interest has occurred among authors pertaining to this study.

\section{REFERENCES}

Baldwin B.G., Sanderson M.J., Porter J.M., Wojciechowski M.F., Campbell C.S. \& Donoghue M.J. (1995). The ITS region of nuclear ribosomal DNA: a valuable source of evidence on angiosperm phylogeny. Annals of the Missouri Botanical Garden 82(2): 247-277.

DOI: https://doi.org/10.2307/2399880

de Boer H. et al. (11 authors) (2018). Convergent morphology in Alpinieae (Zingiberaceae): recircumscribing Amomum as a monophyletic genus. TAXON 67(1): 6-36.

DOI: https://doi.org/10.12705/671.2

Burtt B.L. \& Smith R.M. (1983). Zingiberaceae. In: Revised Handbook to the Flora of Ceylon (eds. M.D. Dassanayake \& E.R. Fossberg), pp. 488-532. Amerind Publication Co. Pvt. Ltd., Colombo.

Droop A.J. (2012). Systematic and biogeographic studies in the genus Amomum Roxb.(Zingiberaceace) in Sumatra. $P h D$ thesis, University of Aberdeen, UK.

Felsenstein J. (1985). Confidence limits on phylogenies: an approach using the bootstrap. Evolution 39(4): 783-791. DOI: https://doi.org/10.1111/j.1558-5646.1985.tb00420.x.

Harris D.J., Newman M.F., Hollingsworth M.L., Möller M. \& Clark A. (2003). The phylogenetic position of Aulotandra (Zingiberaceae). Nordic Journal of Botany 23(6): 725734.

DOI: https://doi.org/10.1111/j.1756-1051.2003.tb00451.x.

Harris D.J., Poulsen A.D., Frimodt-Møller C., Preston J. \& Cronk Q.C.B. (2000). Rapid radiation in Aframomum (Zingiberaceae): evidence from nuclear ribosomal DNA internal transcribed spacer (ITS) sequences. Edinburgh Journal of Botany 57(03): 377-395.

DOI: https://doi.org/10.1017/S0960428600000378.

Huelsenbeck J.P. \& Ronquist F. (2001). MRBAYES: Bayesian inference of phylogenetic trees. Bioinformatics 17(8): 754-755.

DOI: https://doi.org/10.1093/bioinformatics/17.8.754

Johnson L.A. \& Soltis D.E. (1994). matK DNA sequences and phylogenetic reconstruction in Saxifragaceae s. str. Systematic Botany 19(1): 143-156. DOI: https://doi.org/10.2307/2419718

Kaewsri K. (2006). Systematic studies of the genus Amomum Roxb.(Zingiberaceae) in Thailand. PhD thesis, Kasetsart University, Bangkok, Thailand.

Kaewsri W., Paisooksantivatana Y., Veesommai U., Eiadthong W. \& Vajrodaya S. (2007). Phylogenetic analysis of Thai Amomum (Alpinioideae: Zingiberaceae) using AFLP markers. Kasetsart Journal (Natural Science) 41: 213 226.

Karunarathne P., Yakandawala D. \& Samaraweera P. (2015). Important notes on the identity of Alpinia fax (Thwaites) B.L. Burtt \& R.M. Sm. Taiwania 60(4): P204-207. DOI: https://doi.org/10.6165/tai.2015.60.204

Karunarathne P., Yakandawala D. \& Samaraweera P. (2014). On the occurrence of a new variety of Amomum villosum (Family Zingiberaceae) in Central Hills of Sri Lanka. Phytotaxa 172(2): 129.

DOI: https://doi.org/10.11646/phytotaxa.172.2.9

Kiew K.Y. (1982). The genus Elettariopsis (Zingiberaceae) in Malaya. Notes from the Royal Botanic Garden, Edinburgh 40(1): 139-152.

Kress W.J., Liu A.-Z., Newman M. \& Li Q.-J. (2005). The molecular phylogeny of Alpinia (Zingiberaceae): a 
complex and polyphyletic genus of gingers. American Journal of Botany 92(1): 167-178.

DOI: https://doi.org/10.3732/ajb.92.1.167

Kress W.J., Newman M.F., Poulsen A.D. \& Specht C. (2007). An analysis of generic circumscriptions in tribe Alpinieae (Alpinioideae: Zingiberaceae). The Gardens' Bulletin Singapore 59(1 \& 2): 113-128.

Kress W.J., Prince L.M. \& Williams K.J. (2002). The phylogeny and a new classification of the gingers (Zingiberaceae): evidence from molecular data. American Journal of Botany 89(10): 1682-1696.

DOI: https://doi.org/10.3732/ajb.89.10.1682

Kress W.J. \& Specht C.D. (2005). Between cancer and capricorn: phylogeny, evolution and ecology of the primarily tropical Zingiberales. Biologiske Skrifter 55: 459-478.

Kumar P., Sabu M. \& Jayasree S. (2002). Alpinia fax Burtt $\&$ Smith. A new record for South India. Rheedea 12(2): 179-183.

Lamxay V. \& Newman M.F. (2012). A revision of Amomum (Zingiberaceae) in cambodia, laos and vietnam. Edinburgh Journal of Botany 69(1): 99-206.

DOI: https://doi.org/10.1017/S0960428611000436.

Larget B. \& Simon D.L. (1999). Markov Chasin Monte Carlo algorithms for the Bayesian analysis of phylogenetic trees. Molecular Biology and Evolution 16(6): 750-759.

DOI: https://doi.org/10.1093/oxfordjournals.molbev.a026160.

Larkin M.A. et al. (13 authors) (2007). Clustal W and Clustal X version 2.0. Bioinformatics 23(21): 2947-2948. DOI: https://doi.org/10.1093/bioinformatics/btm404.

Larsen K., Lock J.M., Maas H. \& Maas P.J.M. (1998). Zingiberaceae. In: Flowering Plants $\cdot$ Monocotyledons (ed. K. Kubitzki), pp. 474-495. Springer Berlin Heidelberg, Berlin, Germany. DOI: https://doi.org/10.1007/978-3-662-03531-3_49

Minami M., Nishio K., Ajioka Y., Kyushima H., Shigeki K., Kinjo K., Yamada K., Nagai M., Satoh K. \& Sakurai Y. (2009). Identification of Curcuma plants and curcumin content level by DNA polymorphisms in the trnS-trnfM intergenic spacer in chloroplast DNA. Journal of Natural Medicines 63(1): 75-79.

Ministry of Environment (MOE) (2012). Threatened List. National Red List 2012 of Sri Lanka. Conservation Status of the Fauna and Flora, pp. viii + 476. Ministry of Environment, Colombo, Sri Lanka.

Nixon K. C. \& Carpenter J. M. (1996). On simultaneous analysis. Cladistics 12(3): 221-241.

DOI: https://doi.org/10.1111/j.1096-0031.1996.tb00010.x.

Posada D. (2008). jModelTest: Phylogenetic model averaging. Molecular Biology and Evolution 25(7): 1253-1256. DOI: https://doi.org/10.1093/molbev/msn083
Rangsiruji A., Newman M. F. \& Cronk Q. C. B. (2000a). A study of the infrageneric classification of Alpinia (Zingiberaceae) based on the ITS region of nuclear rDNA and the trnL-F spacer of chloroplast DNA. Monocots: systematics and evolution, pp 695-709. CSIRO, Collingwood, Australia.

Rangsiruji A., Newman M. F. \& Cronk Q.C.B. (2000b). Origin and relationships of Alpinia galanga (Zingiberaceae) based on molecular data. Edinburgh Journal of Botany 57(1): 9-37.

DOI: https://doi.org/10.1017/S0960428600000020.

Sakai S. \& Nagamasu H. (1998). Systematic studies of Bornean Zingiberaceae I. Amomum in Lambir Hills, Sarawak. Edinburgh Journal of Botany 55(01): 45. DOI: https://doi.org/10.1017/S0960428600004352

Schumann K. (1904). Zingiberaceae. In: Das Pflanzenreich (ed A. Engler.), pp. 1-458. Wilhelm Engelmann, Leipzig, Germany.

Shaw J. et al. (10 authors) (2005). The tortoise and the hare II: relative utility of 21 noncoding chloroplast DNA sequences for phylogenetic analysis. American Journal of Botany 92(1): 142-166.

DOI: https://doi.org/10.3732/ajb.92.1.142

Sirirugsa P. (2001). Zingiberaceae of Thailand. Biodiversity Research and Training Program, Bangkok, Thailand, pp 63-77. Jirawat Express Co., Ltd, Bangkok, Thailand.

Smith R.M. (1990). Alpinia (Zingiberaceae): a proposed new infrageneric classification. Edinburgh Journal of Botany 47(1): $1-75$.

DOI: https://doi.org/10.1017/S0960428600003140

Swofford D.L. (2003). \{PAUP*. Phylogenetic Analysis Using Parsimony (* and Other Methods). Version 4.\}.

Taberlet P., Gielly L., Pautou G. \& Bouvet J. (1991). Universal primers for amplification of three non-coding regions of chloroplast DNA. Plant Molecular Biology 17(5): 11051109.

DOI: https://doi.org/10.1007/BF00037152

Wu T.-L. \& Larsen K. (2000). Zingiberaceae. In: Flora of China (eds Z.-Y. Wu \& P.H. Raven), pp. 322-377. Sci. Press, Beijing, China.

Xia Y.-M., Kress W.J. \& Prince L.M. (2004). Phylogenetic analyses of Amomum (Alpinioideae: Zingiberaceae) Using ITS and matK DNA Sequence Data. Systematic Botany 29(2): 334-344.

DOI: https://doi.org/10.1600/036364404774195520

Yang Z. \& Rannala B. (1997). Bayesian phylogenetic inference using DNA sequences: a Markov Chain Monte Carlo method. Molecular Biology and Evolution 14(7): 717-724. DOI: https://doi.org/10.1093/oxfordjournals.molbev.a025 811 


\section{Supplementary data}

Supplementary Table 1: GeneBank accessions used in the global phylogeny analysis of gingers in comparison with Sri Lankan species.

\begin{tabular}{|c|c|c|}
\hline Species & Accession no. & Author(s) \\
\hline Amomum stenosiphon & MH603415.1 & Givnish et al., 2018 \\
\hline Elettariopsis triloba & AY769794.1 & Harris et al., 2005 \\
\hline Amomum longipetiolatum & AY769788.1 & Harris et al., 2005 \\
\hline Alpinia aff. calycodes & AY769797.1 & Harris et al., 2005 \\
\hline Amomum petaloideum & AY769789.1 & Harris et al., 2005 \\
\hline Alpinia cf. aenea & AY769796.1 & Harris et al., 2005 \\
\hline Alpinia galanga & KY412470.1 & Anju \& Yusuf, 2016 \\
\hline Amomum uliginosum & AY769790.1 & Harris et al., 2005 \\
\hline Zingiber zerumbet & KY412469.1 & Anju \& Yusuf, 2016 \\
\hline Aтотит sp. & AY769793.1 & Harris et al., 2005 \\
\hline Alpinia purpurata & MH603399.1 & Givnish et al., 2018 \\
\hline Zingiber spectabile & MH603449.1 & Givnish et al., 2018 \\
\hline Amomum compactum & NC_036992.1 & Wu, 2018 \\
\hline Alpinia oxyphylla & KY985237.1 & Gao et al., 2017 \\
\hline Alpinia galanga & KJ609030.1 & Mathew et al., 2014 \\
\hline Amomum glabrum & FJ848631.1 & Auvray et al., 2009 \\
\hline Alpinia zerumbet & MH603400.1 & Givnish et al., 2018 \\
\hline Hedychium coronarium & MH603422.1 & Givnish et al., 2018 \\
\hline Aframomum limbatum & FJ848663.1 & Auvray et al., 2009 \\
\hline Aframomum pilosum & FJ848652.1 & Auvray et al., 2009 \\
\hline Aframomum angustifolium & MH603398.1 & Givenish et al., 2018 \\
\hline Aframomum longiligulatum & FJ848639.1 & Auvray et al., 2009 \\
\hline Renealmia battenbergiana & AY769802.1 & Harris et al., 2004 \\
\hline Renealmia occidentalis & AY769801.1 & Harris et al., 2004 \\
\hline Renealmia alpinia & DQ444491.1 & Sarkinen et al., 2006 \\
\hline
\end{tabular}




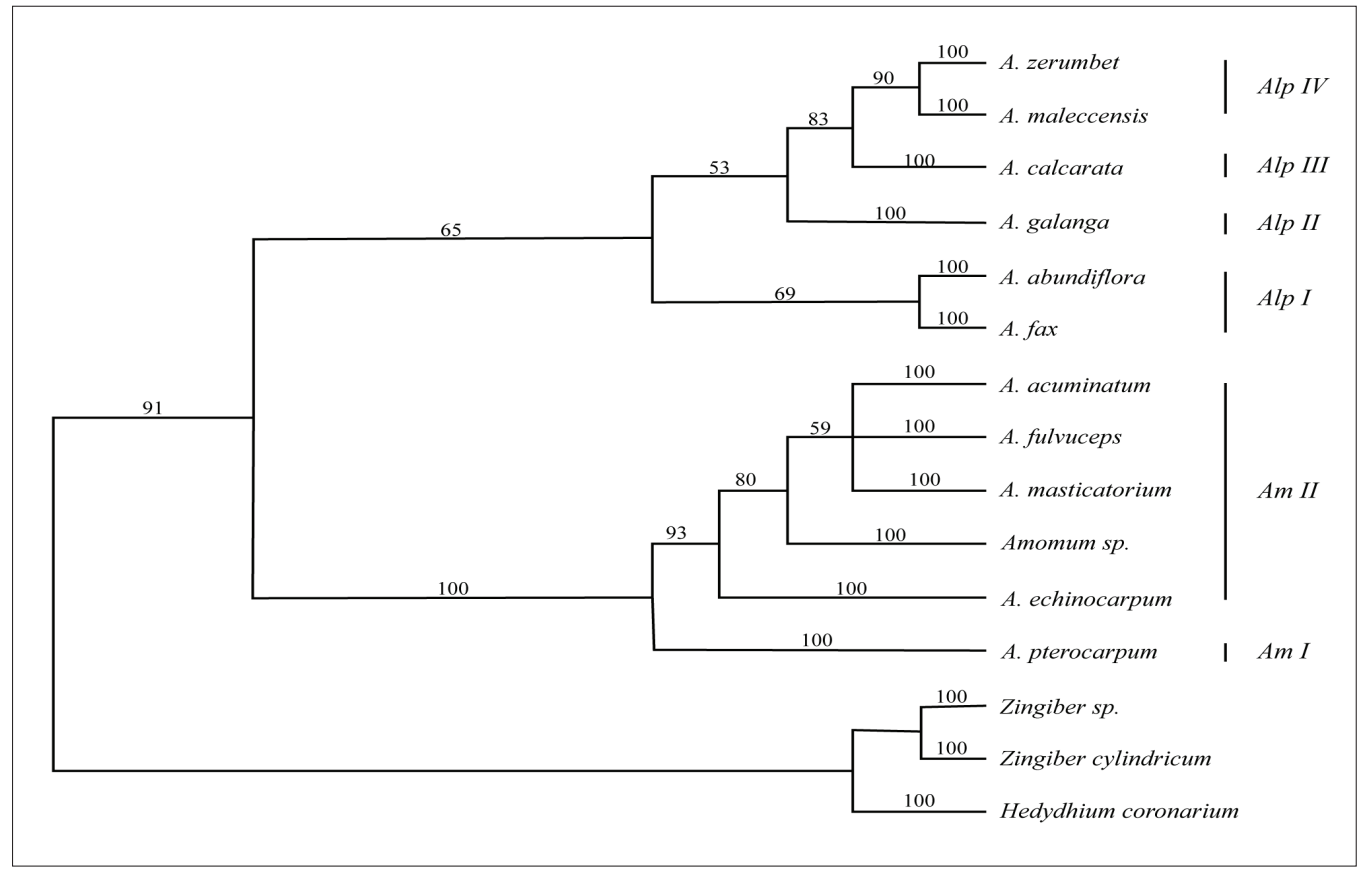

Supplementary Figure 1: One of the best trees resulted from the parsimony analysis of the trn $L-F$ sequence data (length $=579$; consistency index $=0.936$; retention index $=0.982$; rescaled consistency index $=0.920$ ) showing bootstrap values; $\mathrm{A}-$ Alpinia group, $\mathrm{B}-$ Amomum group.

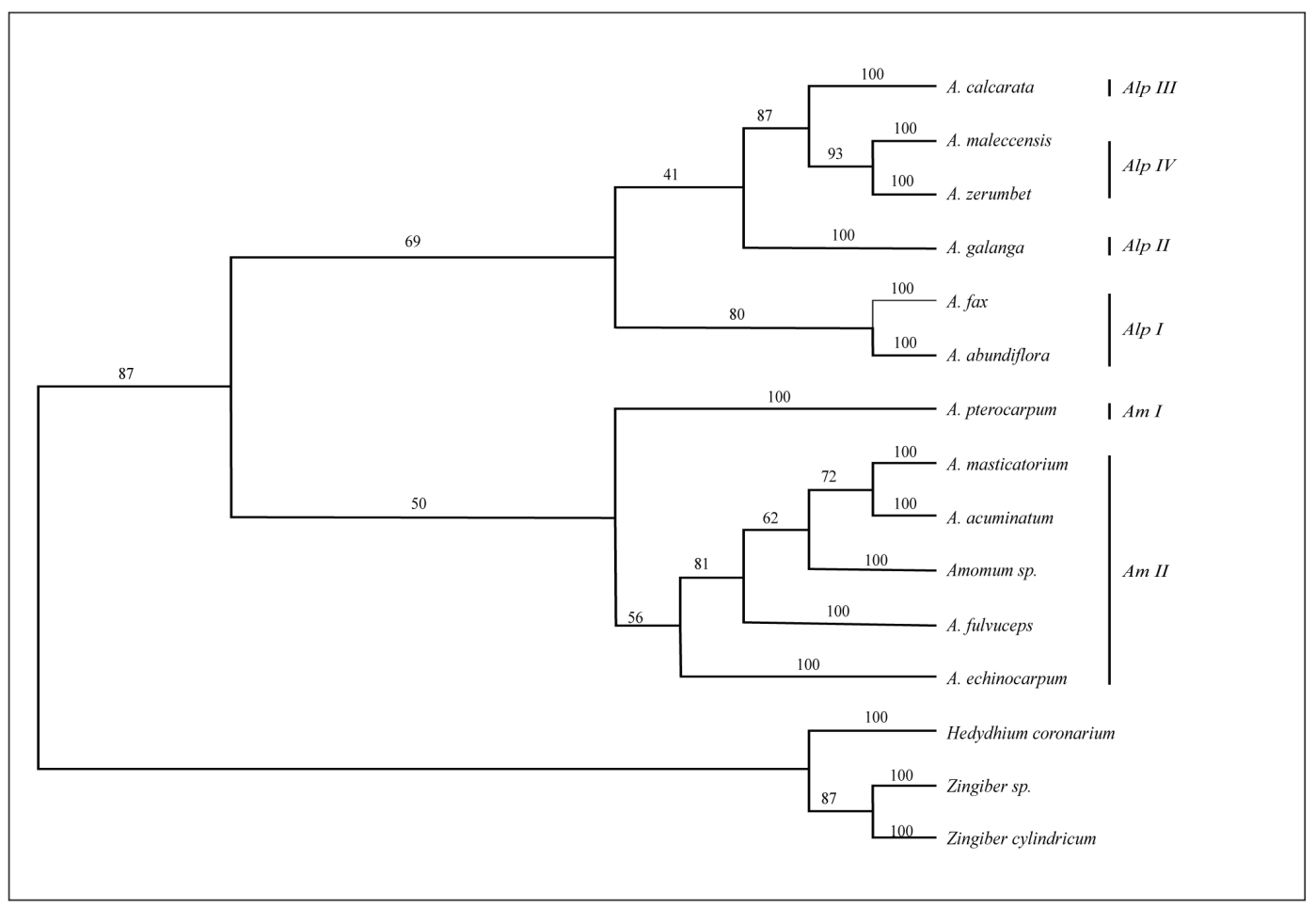

Supplementary Figure 2: One of the best trees resulted from the parsimony analysis of the $\operatorname{trn} S-f M$ sequence data (length $=743$; consistency index $=0.860 ;$ retention index $=0.576$; rescaled consistency index $=0.495$ ) showing bootstrap values; A - Alpinia group, $\mathbf{B}$ - Amomum group. 


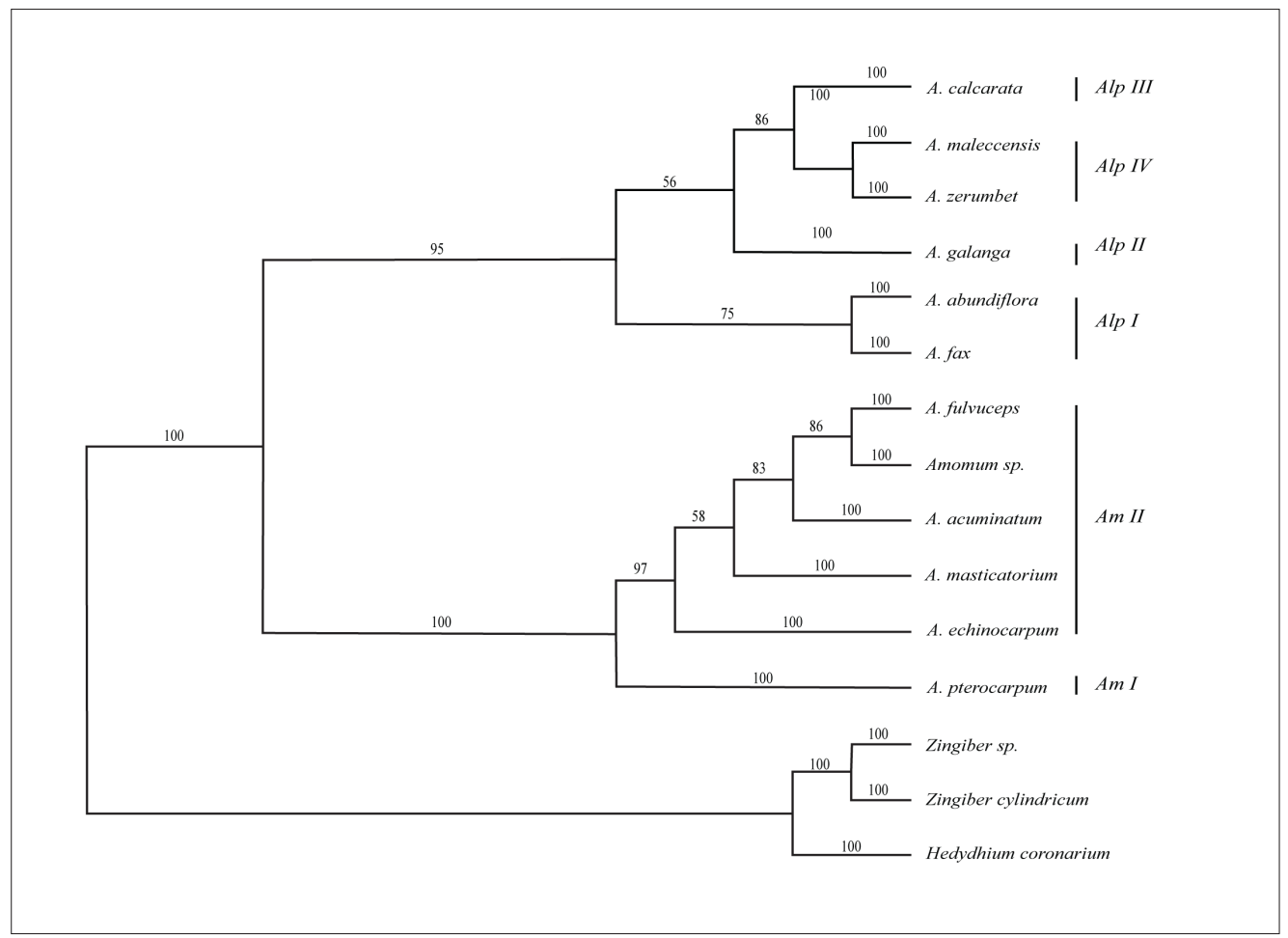

Supplementary Figure 3: One of the best trees resulted from the parsimony analysis of the combined sequence data of trn L-F and trn S-fM (length = 1289; consistency index $=0.887$; retention index $=0.939$; rescaled consistency index $=0.833$ ); branch labels: above - bootstrap values, below - posterior probability; A - Alpinia group, B - Amomum group, A1- Alpinia group without the basal clade of the A group. 